\title{
Text Analysis of Beijing Talent Policy
}

\author{
Wei Zhang', Yujuan Zhang² \\ 1. Beijing Municipal Institute of Science and Technology Information, Beijing, China \\ 2. Beijing Municipal Institute of Science and Technology Information, Beijing, China
}

Keywords: Talent Policy; Text Analysis; Beijing Government

Abstract. This article analysis the changes of Beijing talents policy in the new era. It categorized the policy as five aspects: talent introduction, talent life-support, talent training, Talent motivation, talent entrepreneurship, analyses the current situation of different kind of policy, point out the shortage, and put forward some suggestions.

\section{Introduction}

This paper will analysis ten talent policies in Beijing, including the Beijing Municipal Science and Technology Commission (one policy), Beijing Municipal People's Government (two policies), Zhongguancun (seven policies), the policies received more the 200 million financial support From the support view, we can tell that the policy will cover all aspect of talent. The content of the policy can be refined into five aspects: talent introduction, talent life-support, talent training, Talent motivation, talent entrepreneurship.

\section{Text Analysis of Policy Elements}

In this paper, from the perspective of policy types and continuity, the level of policy support personnel, the provision of special services and security measures, we analyze and compare the data of talent policy.

\subsection{The continuity of policy implementation has maintained a good level}

From the view of support funds, Beijing government spent most funds on entrepreneurial talent policy, account for $52.5 \%$ of the total financial support, talent incentive and talent training accounted for $21.7 \%$ and $21.5 \%$ respectively, the talent life-support policy got the minimum support, the total amount of the proportion is $4.3 \%$.

From the number of policy, there are one talent introduction policy, one talent life-support policy, two personnel training policies, two talent incentive policies, and five entrepreneurial talent policies.

From the timetable for implementation, there are two short-term policies (from 1year to 3 years), three medium-term policies (from 3 years to five years), and four long-term policies (over 5 years). The duration of policy implementation is very vital for the continuity and stability of talent policy, from the issue of policy to the social response, we need time to convey and understand it, so it is a little hard for short-term policy to become fully effective. In Beijing, The current situation of the talent policy shows that it has a good level in the continuity of implementation, which is conducive to the sustainable development of talent introduction and support

\subsection{High-end talent is the focus of Beijing talent policy}

The talent policy can be categorized as two kinds: high-end talent and ordinary talent. High-end talent refers to those who have a leading role in his field, such as pioneering talents, innovation leading talents, leading entrepreneurs, investors, innovation and entrepreneurship leading talent, industry leading talent, Returnees entrepreneurial talent etc. ordinary talent are technical personnel in important field and industry, such as college students, young talents, etc.

Beijing's policy reflects not only rely on talent introduction policy to attract high level talent, but more funds and management will be invested to support higher level entrepreneurial talent, especially tend to small and micro enterprises and innovative talent construction enterprises. Beijing puts a high value on the academic status and education background of personnel; talents who won 
several national awards of science and technology; talents who have invention patent; senior management personnel; talents who have advanced skills etc. These people must has a certain achievements in one aspect or a particular area, and these people's innovation ability is relatively strong, they have good foundation of innovation, In Beijing these indexes are mentioned in all talent policy.

In addition, Beijing has a strong demand on scientific research and innovation, so more policy emphases on cutting-edge academic talents such as academicians, national major award winner, director of country's key laboratories and talent in the list of Thousand Talents program.

\subsection{Funding policy is various measures}

With its own industrial characteristics and economic capacity, Beijing is trying to carry out institutional innovation in the formulation of special subsidy policies. There are different amount of investment, the way of investment, the level and type of talents in different talents policy, and each of them is compared and analyzed.

Policy tools can be briefly summarized as the following two aspects. Financially, for overseas talent, young talent, university staff and students, high-end entrepreneurial talent the policy will provide one-time subsidies; give rent subsidies to Zhongguancun high-end entrepreneurial talent base. According to the current policy of oversea talent, Zhongguancun provides financing guarantee for high level talents, entrepreneurship loans and other support.

The preferential policies provide various training services to all kinds of talents in zhongguancun, provide the opportunity to communicate for high end talents in the form of training, so as to promote the talents of innovation, entrepreneurship and technological cooperation. The policy also provide subsidized interest to the project of public rental housing construction, rent subsidies to project management, investment or property units, and support funds to project financing of public rental housing construction. Talent policy will provide convenient medical services; enjoy the priority right of renting public rental house, provide accommodation, entry and exit conditions.

\subsection{Talent introduction and entrepreneurship is the main focus of policy}

Beijing talent policy mainly issued by three government departments, Beijing municipal government, Beijing Science and Technology Commission and Zhongguancun, each department policy relatively independent, there is no cross and repeated content. Beijing Science and Technology Commission focus on talent training, Beijing municipal government focus on talent introduction and motivation, Zhongguancun focus on the talent introduction and entrepreneurship. Both from the number of policy and financial support, talents entrepreneurship policy are the most important. Five talents entrepreneurship policy account for more than $50 \%$ of financial support, two policies contains the content of the talent introduction.

Especially the zhongguancun high-end talent program, not only including talent introduction, also contains the talent ability, performance and contributions as the main basis, establishing the quantitative and qualitative analysis of talent evaluation system and life-support measurement. Beijing talent policy has been paying more attention on two aspects: talent introduction and entrepreneurship.

Talent training policy, science and technology talent plan and leading talent training plan has entered the stage of branding, refinement. On the training modes, Beijing require training talents of science and technology, and at the same time establish science and technology innovation team, led by science and technology talents, encourage the innovation achievements into productivity, emphasis entrepreneurial effect. science and technology talent plan is clearly targeted on young researcher, through the way of projects Application, the plan can training the researcher, and provide communication platform for young talents, share the academic experience, which will be linked to upstream and downstream industry chain

Although there is only one policy about talent life-support, the investment is the minimum, but in the process of policy implementation, talent introduction and entrepreneurship policy contains content of talent life-support, Since 2010, zhongguancun implement public rental housing projects, during six years, the government has built 23,000 houses, provide services for 600 companies, 
accumulative total support fund 125 million, solve the transitional housing needs of 30,000 people. Each park district in Zhongguancun has established public housing rent management system and method, has carried on the talents of public housing construction work. Thus, Beijing talent life-support policy, especially the public housing policy has strong leverage and diffusion effect.

Beijing spent large money on talent incentive policy; especially emphasis on the entrepreneurial talent incentive, for high-level innovative talents, government provides one-time subsidies or reward, up to 1 million, this kind of policy get mostly support of all the talent policy. Incentives measures connect with supporting measures, to high-level innovative talents, government will provide science and technology projects, work place, equity incentive, patent incentives.

\section{Existing Problems of Talent Policy}

\subsection{The coverage of talent policy is very low}

In Beijing, $70 \%$ of talent policy aims at high-end talent, only a small amount of talent training and entrepreneurship policy aim at young talent. Especially in zhongguancun nearly $90 \%$ of talent policy system support high-end talent of company, it also reflects the policy support of talent policy is insufficient.

\subsection{The level of the talent policy is not reasonable}

Reasonable talent policy system should include the introduction of talent, training, incentive, life support and entrepreneurship, five basic modules, and five basic module should be balance as a whole, constitute the integrity of talent policy and systematic. From the perspective of the composition, talent introduction and entrepreneurship policy is the vast majority of talent policy system, from the policy number; talent training, talent incentive, and talent life support policy occupy a relatively low proportion. A perfect Beijing talent policy system, should combine with the policy effectiveness evaluation, fine the shortage each policy module, at the same time, improve and supplement to the existing problems. In particular, the introduction of talent, training and incentive policies can improve the effectiveness of talent policy; this policy module should be strengthened.

In practice, compared with other regions of the country, the talents training of and introduction are in a state of unequal, and Beijing talent training policy lags behind. In Beijing, the policy focus on "high-end" and "urgent" and "industrialization" as the orientation, development of strategic is emerging industries, attracting a number of domestic and international talents and top technical team, focus on the introduction of talent, neglects talent training. By comparing with the other provinces, Beijing talent training policy is weak. From the point of financial support, the intensity is less than Guangdong and Jiangsu, in Beijing, for high-end talent, the support form is funding the research team, 60-80 million, but can not guarantee the funding to cover the core staff of the team. From the number of talent training, obviously weaker than Zhejiang and Jiangsu, and did not form a talent gradient training model. In the introduction of talent, there is no division of the target talent, but also failed to develop different policies and measures according to the characteristics of domestic and foreign demand for talent. There is no talent category about the kind of talent we need. Also not develop talent identification approach, resulting in the lack of clear objectives and policies in the formulation and implementation.

In terms of talent life support policy, there are a variety of means, mostly on life and entrepreneurship, support content are scattered in different types of files, there is no specialized talent life support policy.

In terms of talent incentive, the incentive and the service policy account for the vast majority of the high-level talent policy system, lack of individual incentives for different high-level talents. In practice, the spirit incentive is not enough; the material incentive is still the main incentive style. In the process of introduction, government will give a one-time reward, higher reward standards, better life standard, but, after introduction, the contribution of talent is not linked to the corresponding achievements. 


\section{3 features of talent introduction policy are not clear}

The strategy of introduction is: urgent need, key breakthrough, there is more welfare policy, development policy is relatively simple. In content of welfare policy, the structure is the same as other parts of the country; difference is mainly reflected in the policy efforts.

Moreover, in the way of introduction, Beijing is still in the stage of attracting talents through welfare policies, such as venture capital, housing welfare, financial incentives and so on. Now talent development policy is not enough, there is no follow-up training and development measures, did not pay attention to the development of talent career, it will not only cause frequent transfer of intellectuals, may also lead to talent outflow.

\subsection{Evaluation mechanism is not reasonable}

There is no evaluation mechanism in Beijing talent policy, for the talents in enterprises, research institutes, there is no effective supervision and assessment mechanism aim at their performance and radiation effects, in terms of policy evaluation there is no effective evaluation of talent policy, can not scientifically evaluated the effect of the policy.

\section{Suggestions}

Talent introduction, training, incentive, life support and entrepreneurship influence each other, and promote each other, we should pay more attention to talent training and motivation, improve the system of training, and life support, etc.

In term of introduction and entrepreneurship, we should issue the talent policy, based on the difference of industry. As for talent training, reference the experience of the zhejiang and jiangsu, attaches great importance to improve the research team, support different talent, especially young talent. From the point of talent motivation, we can learn the successful experience of developing country, improve the reward system.

Moreover, we should emphasis the development of talent, Promote the development of talents in the field of work and research. During the policy implementation, in order to optimize policy, we should evaluate the effect of policy, formalize more attracting talent policy.

\section{Reference}

[1] JI JY, ZHU YB. Research on the Flow of Scientific and Techn0109ical Personnel in China Based on Panel Data[J]. Population \&Economics, 2008, (5).

[2]Abdullah H, Rose R C，Kumar N.Human resource development strategies: The Malaysian scenario[J].Journal of Social Sciences, 2007，2:13-22.

[3]Kruti Dholakia-Lehenbauer and Euel Elliott.Decisionmaking,Risk,And Uncertainty:An Analysis of Climate Change Policy[J].Cato Journal,2012,32(3):539-556 